Case

Report

\title{
A Case Report of Pulmonary Thromboendarterectomy for Chronic Thromboembolism in a Patient with Protein C Deficiency
}

\author{
Susumu Isoda, MD,${ }^{1}$ Tamizo Kimura, MD, ${ }^{1}$ Kenji Nishimura, MD, ${ }^{1}$ \\ Nozomu Yamanaka, PhD,${ }^{1}$ Shingo Nakamura, PhD,${ }^{1}$ Motomi Ando, MD, ${ }^{2}$ \\ and Tadaaki Maehara, MD ${ }^{1}$
}

\begin{abstract}
The patient was a 41-year-old female with chronic thromboembolism. She was admitted to an affiliated hospital with exertional dyspnea, leg swelling, and hemoptysis, and she was treated medically with tissue plasminogen activator and warfarin therapy. When transferred to our hospital, she was oxygen-dependent with severe dyspnea. A pulmonary arteriogram showed occlusion and stenosis of the pulmonary arteries. Cardiac catheterization revealed marked pulmonary hypertension. The lung perfusion scintigram showedmultiple defects in the right and left lungs. Preoperative laboratory data showed a markedly decreased protein $C$ antigen level. Magnetic resonance angiography showed that a myoma uteri compressed the pelvic vein and that she had deep vein occlusion of the left leg. After the administration of an epoprostenol infusion and the insertion of an inferior vena cava filter, she underwent an operation. Under deep hypothermia, the bilateral pulmonary artery was opened and an endarterectomy was performed during intermittent circulatory arrest. After surgery, her pulmonary vascular resistance was in the normal range. Her New York Heart Association functional classification changed from class IV to class I. She has been in good condition for 7 years since the surgery.
\end{abstract}

Keywords: chronic pulmonary embolism, protein $\mathrm{C}$ deficiency, pulmonary thromboendarterectomy

\section{Introduction}

Medical treatment for chronic pulmonary thromboembolism has a poor survival, ${ }^{1)}$ whereas surgical treatment

${ }^{1}$ Department of Cardiovascular Surgery, National Defense Medical College, Saitama, Japan

${ }^{2}$ Department of Cardiovascular Surgery, Fujita Health University, Aichi, Japan

Received: March 7, 2013; Accepted: June 7, 2013

Corresponding author: Susumu Isoda, MD. Department of Cardiovascular Surgery, National Defense Medical College, 3-2

Namiki, Tokorozawa, Saitama 359-8531, Japan

Email: isodas@ndmc.ac.jp

(C)2014 The Editorial Committee of Annals of Thoracic and Car-

diovascular Surgery. All rights reserved. provides a better prognosis. The protein $\mathrm{C}$ system is a natural profibrinolytic system consisting of protein $\mathrm{C}$ and protein $\mathrm{S}$ (which are vitamin K-dependent plasma proteins) and thrombomodulin (which is a surface protein of endothelial cells). ${ }^{2)}$ Protein C-deficient patients between the ages of 15 and 40 years usually develop venous thrombotic complications with a high incidence of deep venous thrombosis and pulmonary embolism. ${ }^{3,4)}$ Medical treatment of patients with protein $\mathrm{C}$ deficiency includes the administration of heparin, fresh frozen plasma, warfarin, and protein $\mathrm{C}$ extract. The effect of recombinant human activated protein $\mathrm{C}$ infusion is controversial. ${ }^{5)}$ We have surgically treated pulmonary thromboembolismsuccessfully in a patient with protein $\mathrm{C}$ deficiency. 

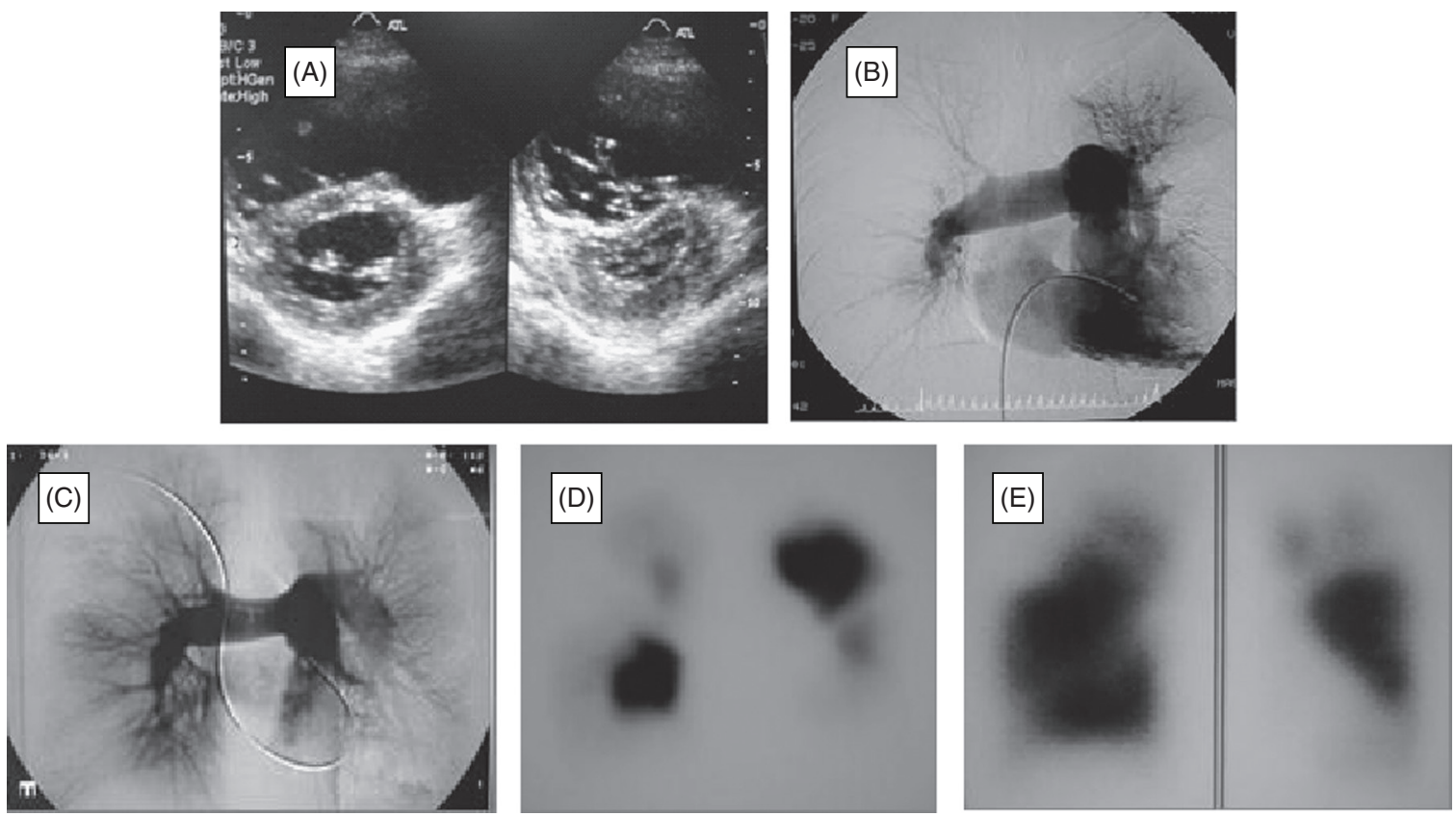

Fig. 1 (A) (Left) The transectional view on the echocardiogram during diastole shows marked enlargement of the right ventricle. (Right) The left ventricle is compressed with ventricular septum straightening during systole. (B) Preoperative pulmonary angiography shows multiple occlusions. (C) Postoperative pulmonary angiography shows marked improvement in perfusion. (D) Preoperative pulmonary perfusion scintigram shows multiple defects in both lobes. (E) Postoperative pulmonary perfusion scintigram shows marked improvement in perfusion.

\section{Case Report}

A 41-year-old female presented to an affiliated hospital with exertional dyspnea, hemoptysis, and leg swelling. She had a history of myoma uteri at age 28 , hyperlipidemia at age 40, and smoking 20 cigarettes per day for 25 years. Enhanced computed tomography and pulmonary angiography indicated a diagnosis of pulmonary thromboembolism. Heart catheterization showed she had a pulmonary hypertension pressure of $70 / 24 \mathrm{mmHg}$. She was administered tissue plasminogen activator. This was followed by the administration of sequential heparin and warfarin therapy. Patient was discharged from the hospital with home oxygen therapy. Her compliance with warfarin therapy was not good since it resulted in a large amount of bleeding at menstruation. After she stopped taking warfarin, her dyspnea worsened. She was re-admitted to the previous hospital, and her New York Heart Association (NYHA) functional class changed from class III to class IV. She was transferred to our hospital for surgical intervention.

On admission to our hospital, her height was $159 \mathrm{~cm}$; body weight, $59 \mathrm{~kg}$; blood pressure, 120/68 mmHg; and pulse rate, 70 beats per minute. Chest auscultation showed that heart sound II was increased and widely split. Her liver was palpable for 3 finger widths. A myoma uteri was palpable at the lower abdomen. She had mild bilateral leg edema.

A biochemistry study revealed that the brain natriuretic peptide level was increased at $507 \mathrm{pg} /$ microliter. Protein $\mathrm{C}$ antigen was $46 \%$ and the protein $\mathrm{C}$ activity was $32 \%$. Protein S antigen was $99 \%$. Blood gas analysis revealed marked hypoxemia at $47.5 \mathrm{mmHg}$ on room air. Electrocardiography showed right axis deviation and inversion of the $\mathrm{T}$ waves at leads II, III, aVF, and V1 through V4. Chest X-ray showed cardiomegaly with a cardiothoracic ratio of $60.4 \%$. Echocardiography showed a left ventricular ejection fraction of $48 \%$, systolic ventricular septal straightening (Fig. 1A), and an estimated pulmonary artery pressure of $84 \mathrm{mmHg}$. Heart catheterization showed that her pulmonary artery pressure was 71/22 (mean 41) mmHg; pulmonary capillary wedge pressure, 14/6 (mean 10) $\mathrm{mmHg}$, right atrial pressure, 21/6 (mean 13) $\mathrm{mmHg}$; blood pressure, $110 / 76 \mathrm{mmHg}$; cardiac index, $2.2 \mathrm{~L} / \mathrm{m}^{2}$; and pulmonary vascular resistance, 710 dyn-s/cm 5 . Enhanced computed tomography showed a thromboembolism of the pulmonary artery.

Pulmonary angiography revealed multiple occlusions 
(A)

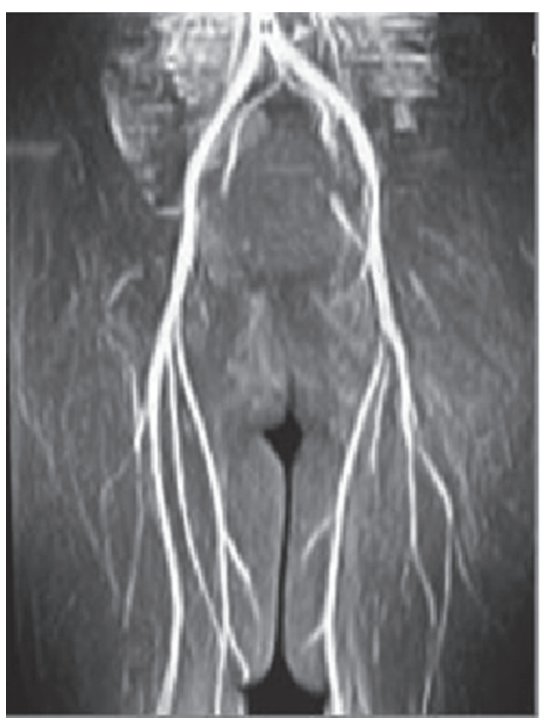

(B)

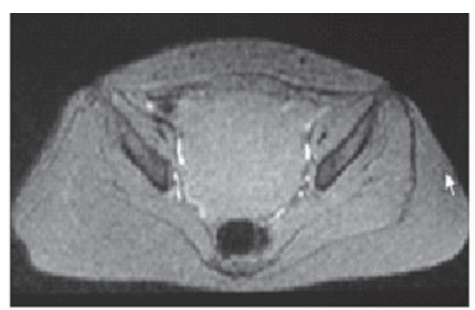

(C)

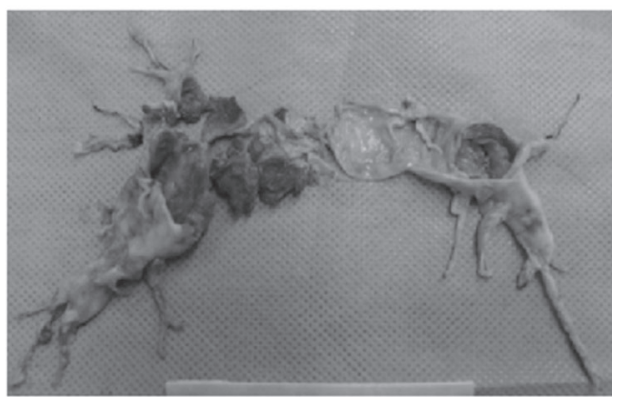

Fig. 2 (A) Magnetic resonance imaging shows a myoma uteri compressing the pelvic vein and shows deep vein occlusion in the left leg. (B) Computed tomography scan of the pelvis shows a myoma uteri compressing the pelvic vein. (C) The surgically resected pulmonary thromboendartery.

Table 1 Preoperative and postoperative hemodynamic data

\begin{tabular}{lcc}
\hline & Preoperation & Postoperation \\
\hline CTR $(\%)$ & 60.4 & 49.5 \\
$\mathrm{PaO} 2(\mathrm{mmHg}$ [room air] & 47.5 & 76.5 \\
$\mathrm{PA}(\mathrm{mmHg})$ & $71 / 22(41)$ & $28 / 7(15)$ \\
$\mathrm{PVR}\left(\mathrm{dyn}-\mathrm{s} / \mathrm{cm}^{5}\right)$ & 710 & 198 \\
$\mathrm{CI}\left(\mathrm{L} / \mathrm{min} / \mathrm{m}^{2}\right)$ & 2.2 & 3.1 \\
$\mathrm{NYHA} \mathrm{class}$ & $\mathrm{IV}$ & II (current I) \\
$\mathrm{BNP}(\mathrm{pg} / \mu \mathrm{L})$ & 507 & 75.6 \\
Oxygen therapy & Rest, 3L; exercise, 6L & None \\
\hline
\end{tabular}

CTR: cardiothoracic ratio; BNP: brain natriuretic peptide

(Fig. 1B). Pulmonary perfusion scintigraphy showed multiple defects in both lobes (Fig. 1D). Magnetic resonance imaging showed a myoma uteri compressing the pelvic vein and deep vein occlusion in the left leg (Fig. 2A). Computed tomography of the pelvis showed that a myoma uteri compressed the pelvic vein (Fig. 2B). She was administered epoprostenol (i.e., prostaglandin I2), which was started at $2 \mathrm{ng} / \mathrm{kg}$ per minute and increased $1 \mathrm{ng}$ every two days until reaching $5 \mathrm{ng} / \mathrm{kg}$ per minute; she was then maintained at $5 \mathrm{ng} / \mathrm{kg}$ per minute until the operation. Seven days before surgery, an inferior vena cava filter was inserted at the inferior vena cava at the caudal side of renal vein junction; it was not removed after the surgery. A thromboendarterectomy was performed. After performing a median sternotomy, cardiopulmonary bypass was established by cannulation of the ascending aorta and by two caval cannulations. The patient was cooled to $16.9^{\circ} \mathrm{C}$ at the nasopharynx. The aorta was cross-clamped and cardiac arrest was accomplished by using cold-blood cardioplegia. During 5 circulatory arrests-each lasting for 15 minutes - thromboendoarterectomy was performed through a right and a left pulmonary incision (Fig. 2C). ${ }^{6}$ Weaning the patient from cardiopulmonary bypass was uneventful. There was mild bleeding from the tracheal tube but it was reduced by using positive end-expiratory pressure treatment. The aortic clamp time was 172 minutes and the cardiopulmonary bypass time was 301 minutes. The operation time was 536 minutes. After the operation, intravenous heparin administration was initiated, followed by warfarin administration. She had rather persistent bleeding from the tracheal tube and required 7 days before she could be extubated. On postoperative 
day 9, she was discharged from the intensive care unit. Postoperative pulmonary angiography and perfusion scintigraphy showed marked improvement (Fig. 1C and 1E). Table 1 shows her postoperative hemodynamic data. All parameters improved markedly. She has been followed for 7 years and 5 months, and has been in good condition with a New York Heart Association functional classification of class I. We planned the prothrombin time/international normalized ratio (PT/INR) to range from 2 to 3 to control warfarin postoperatively, However, the control was not very satisfactory-the PT/INR ranged from 0.98 to 4.44 . During the follow-up period, occasional massive bleeding at menstruation also induced iron deficiency anemia for which the hemoglobin concentration ranged from $7.4 \mathrm{~g} / \mathrm{dL}$ to $14.4 \mathrm{~g} / \mathrm{dL}$.

\section{Discussion}

Pulmonary emboli are normally resolved by active fibrinolysis. Pulmonary scanning used in one study showed complete dissolution of a thromboembolism 4-8 days after the event; $22 \%$ of patients continued to have signs of the disease and $0.5 \%$ to $4 \%$ of the patients developed pulmonary hypertension. ${ }^{2)}$ Once chronic pulmonary thromboembolism has developed, patients undergoing medical treatment have a poor survival, whereas surgical treatment provides a better prognosis. ${ }^{\text {) }}$

The protein $\mathrm{C}$ system is a natural profibrinolytic system that consists of protein $\mathrm{C}$ and protein $\mathrm{S}$ (which are vitamin K-dependent plasma proteins) and thrombomodulin (which is a surface protein of endothelial cells). ${ }^{2}$ Since protein C-deficient patients have poor fibrinolytic activity, complete dissolution of a thromboembolism is difficult and recurrent attacks of thromboembolisms often occur. Protein C-deficient patients who are between the ages of 15 and 40 years usually develop venous thrombotic complications and have a high incidence of deep venous thrombosis and pulmonary embolism. ${ }^{3)}$ Medical treatment of protein C-deficient patients includes the administration of heparin, fresh frozen plasma, warfarin, and protein $\mathrm{C}$ extract. Our patient had protein $\mathrm{C}$ deficiency and multiple risks for thromboembolism (e.g., high lipidemia, smoking, and compression of the pelvic vein by a large myoma uteri). After she was diagnosed with pulmonary thromboembolism, she was medically treated by the administration of tissue plasminogen activator, heparin, warfarin, and home oxygen therapy. However, this therapy was unsuccessful. Recombinant human activated protein $\mathrm{C}$ was not administered to our patient since its effect is controversial ${ }^{5)}$ and the cost-to-benefit relationship is unclear. Our patient did not experience purpura fulminans due to an extreme decrease in protein $\mathrm{C}$ activity; however, we suspect a relationship existed between the severe instability in warfarin control and protein $\mathrm{C}$ deficiency in our patient.

Surgical treatment of the pulmonary thromboembolism was dramatically successful for our patient. Because medical treatment provides poor survival, ${ }^{1)}$ the mortality rate of $5 \%$ to $9 \%^{6-8)}$ seems to be an acceptable risk for the surgical treatment of this disease. The expected longterm survival rate after surgery is $75 \%,{ }^{9)}$ whereas our patient had a dramatic improvement of heart failure during observation. There was no major morbidity, except deterioration resulting from warfarin-associated excessive menstrual bleeding. We believe that surgical treatment is quite beneficial and has an acceptable risk.

In 2010, there were 44 surgical cases of chronic pulmonary thromboembolism in Japan ${ }^{10)}$ and in 2011, there were 1288 registered chronic thromboembolism reported by the Japan Intractable Diseases Research Foundation. Despite this, most physicians still seem reluctant to surgically correct chronic thromboembolism. In technical aspect of surgical treatment, bilateral pulmonary treatment via median sternotomy, good visualization with deep hypothermic circulatory arrest, and endarterectomy in an adequate layer without perforation of pulmonary artery or inadequate endoarterectomy. ${ }^{6}$ ) If perforation of the pulmonary artery occurs, suturing from the inside is the first choice to correct it. If reperfusion pulmonary edema or airway bleeding prevents a satisfactory improvement in hemodynamic data after surgery, percutaneous cardiopulmonary support should be attempted to lower the pulmonary artery pressure. ${ }^{11)}$ In our patient, we made a rather deep dissection in one portion of the pulmonary artery, which seemed very thin and rather reddish. We did not stitch at the lesion site; therefore, postoperative percutaneous cardiopulmonary support was unnecessary.

The prevention of recurrent pulmonary embolisms is important. Preoperative inferior vena cava filter implantation and lifelong warfarin administration is important to avoid recurrent attacks. In our patient, residual deep vein thrombosis was present in the femoral vein, and an inferior vena cava filter was implanted before surgery. The filter was not removed after surgery. We now believe that perioperative or permanent inferior vena cava filter implantation is quite important in preventing recurrent attacks that may be fatal. Our patient was administered perioperative heparin infusion and postoperative long-term 
warfarin.

Medical treatment for chronic thromboemolism includes beraprost, ${ }^{12)}$ epoprostenol, ${ }^{13)}$ bosentan, ${ }^{14)}$ and sildenafil. ${ }^{15}$ These drugs are used for primary pulmonary hypertension, which is similar pathologically with chronic thromboembolic pulmonary hypertension and pure pulmonary hypertension. ${ }^{16)}$ Preoperative intravenous epoprostenol administration is attempted as a pretreatment for patients undergoing pulmonary endoarterectomy, and we administered this treatment to our patient. The medical literature indicates that the effect of perioperatively administering epoprostenol for chronic pulmonary thromboembolism seems promising, ${ }^{13)}$ but its clinical effect before surgery has not been clearly demonstrated in our patient.

\section{Conclusion}

This is a case report of a surgically treated pulmonary thromboembolism in a protein C-deficient patient. After preoperatively implanting a vena cava filter in the patient, a surgical pulmonary thromboendarterectomy was performed. Subjective and objective marked improvement was achieved. We did not use recombinant human activated protein $\mathrm{C}$, but instead used warfarin and heparin during the perioperative period. Epoprostenol was administered perioperatively.

\section{Disclosure Statement}

Susumu Isoda and other authors have no conflict of interest.

\section{References}

1) Riedel M, Stanek V, Widimsky J, et al. Longterm follow-up of patients with pulmonary thromboembolism. Late prognosis and evolution of hemodynamic and respiratory data. Chest 1982; 81: 151-8.

2) Briffa NP, Wilson I, Clarke DB. Surgical treatment of pulmonary hypertension in protein $\mathrm{C}$ deficiency. $\mathrm{Br}$ Heart J 1991; 66: 460-2.

3) Marlar RA, Mastovich S. Hereditary protein C deficiency: a review of the genetics, clinical presentation, diagnosis and treatment. Blood Coagul Fibrinolysis 1990; 1: 319-30.
4) Yoshida M, Mukohara N, Obo H, et al. Pulmonary thromboendarterectomy for chronic pulmonary thromboembolism in protein $\mathrm{C}$ deficiency. Jpn J Thorac Cardiovasc Surg 2006; 54: 70-4.

5) Benedetto BJ, Houston MA. A case report of a new pulmonary embolism occurring in a patient receiving continuous infusion of recombinant activated protein C. World J Emerg Surg 2006; 1: 23.

6) Jamieson SW, Auger WR, Fedullo PF, et al. Experience and results with 150 pulmonary thromboendarterectomy operations over a 29-month period. J Thorac Cardiovasc Surg 1993; 106: 116-26; discussion 126-7.

7) Thistlethwaite PA, Kaneko K, Madani MM, et al. Technique and outcomes of pulmonary endarterectomy surgery. Ann Thorac Cardiovasc Surg 2008; 14: 274-82.

8) Ando M, Yamashita M, Sato M, et al. [Surgical treatment for chronic pulmonary thromboembolism]. Nihon Geka Gakkai Zasshi 2005; 106: 252-7. (in Japanese)

9) Archibald CJ, Auger WR, Fedullo PF, et al. Long-term outcome after pulmonary thromboendarterectomy. Am J Respir Crit Care Med 1999; 160: 523-8.

10) Kuwano H, Amano J, Yokomise H. Thoracic and cardiovascular surgery in Japan during 2010: annual report by The Japanese Association for Thoracic Surgery. Gen Thorac Cardiovasc Surg 2012; 60: 680-708.

11) Sato M, Ando M, Muto A, et al. Two cases of chronic pulmonary thromboembolism saved by postoperative use of a percutaneous cardiopulmonary support device. Ann Thorac Surg 2006; 82: 314-6.

12) Ono F, Nagaya N, Okumura H, et al. Effect of orally active prostacyclin analogue on survival in patients with chronic thromboembolic pulmonary hypertension without major vessel obstruction. Chest 2003; 123: 1583-8.

13) Nagaya N, Sasaki N, Ando M, et al. Prostacyclin therapy before pulmonary thromboendarterectomy in patients with chronic thromboembolic pulmonary hypertension. Chest 2003; 123: 338-43.

14) Hoeper MM, Kramm T, Wilkens H, et al. Bosentan therapy for inoperable chronic thromboembolic pulmonary hypertension. Chest 2005; 128: 2363-7.

15) Reichenberger F, Voswinckel R, Enke B, et al. Longterm treatment with sildenafil in chronic thromboembolic pulmonary hypertension. Eur Respir J 2007; 30: 922-7.

16) Galiè N, Kim NH. Pulmonary microvascular disease in chronic thromboembolic pulmonary hypertension. Proc Am Thorac Soc 2006; 3: 571-6. 